GRADUATE JOURILL

\section{Defensive moves}

Every PhD student knows about that time of year when the defence announcements come flooding in. The two months leading up to graduation mark the time when everyone seems to be defending their thesis. Because I am nearing the end of my sixth year, the defence season is a somewhat sensitive time for me. The notices I've been getting recently are mostly for my classmates, the people with whom I started graduate school.

Like a race, some people who set out at the same time as me have already moved on, some are now crossing the finishing line and some still have a way to go. Notices of their upcoming defences generate mixed emotions. I'm genuinely happy for my friends, sad to see them go and sad to be left behind.

But the defences of the classes both above and below mine generate mostly negative emotions. For thcse who started graduate school after me, I can only be ervious that their peth was shorter than mine. For those who started graduate school before me, I worry that I too could find myself in that seventh, eighth or ninth year. I know logically that the length of graduate education is influenced by many factors outside my control. Still, as this defence season begins, I truly hope that I am not around to witness the next one. Anne Margaret Lee is a graduate student at Harvare Universilty.

\title{
SCIENTISTI
}

\section{Postdoc power}

$\square$ he situation for postdocs at the European Molecular Biology Laboratory (EMBL) in Heidelberg, Germany, and its four outstations (at Hinxton, Hamburg, Rome and Grenoble), resembles that in many smaller institutions around the world. EMBL postdocs generally lack organization and a unified voice.

So when a couple of brave fellows last year drafted a proposal for bringing colleagues from all five sites together for a 'retreat' — without management or principal investigators - the director-general and senior scientists endorsed the concept.

Initially many postdocs were sceptical of the retreat and resented the time it took away from the lab. But after the first session, the 100 or so participants began to praise the organizers, the speakers and the forum in general.

The broad nature of life-science research at EMBL made the retreat, to me at least, one of the most exciting and stimulating scientific meetings I have ever attended. The talks ranged from fluorescent mice to software that read papers for us - pausing briefly to poke out the eyes of embryonic worms and to jellify fish. The absence of supervisors meant that people (or perhaps just me) felt free to ask more naive questions than they would have dared had the boss been there. And enforced mixed seating over meals resulted in more than a few fledgling collaborations.

An equally important part of the retreat focused on career development. Speakers from the academic world introduced us to the next steps on the path of leadership - and spoke of the pressures, pitfalls and satisfactions these responsibilities might bring. Industry, publishing and intellectual-property speakers showed us an alternative world of career options, which is much broader than we are led to believe in our early research years.

The feedback from this retreat was overwhelmingly positive. The session on postdoc organization brought up many of the issues we often feel we face alone: payment, security and establishing our positions. It showed that far from being silent workers uninterested in the world around, we want to improve postdoctoral positions for ourselves and those who will follow. Everyone I spoke to had realized that this is the way forward, that a postdoctoral association will only be beneficial and that we are a surprisingly large, aggressive and driven group. We are postdoc.

Hear us roar. Jacinta Lodge is a pestlec at EMBu's Hamburg sitte.
- ver since he was 12 years old, Kenneth Peach has been L fascinated with the stars and interested in uncovering how the Universe works. This passion led his career down a path towards physics. With his appointment in April as the first director of the John Adams Institute for Accelerator Science, based in Oxford and London, one of his main goals is to ensure that the next generation of

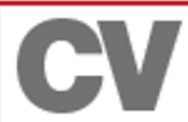
1998-2005: Director, particle physics, Council for the Central Laboratory of the Research Council, Rutherford Appleton Laboratory, Oxfordshire, UK. 1996-2002: Personal chair in particle-physics experiments, University of Edinburgh, UK. 1996-98: Deputy leader of the Particle Physics Experiments Division, European Centre for Nuclear Research, Geneva, Switzerland.

1992-96: Reader, Department of Physics and Astronomy, University of Edinburgh, UK. scientists can do their job investigating the mysteries of the Universe.

"It is a privilege and a challenge to have the task of defining the ways accelerator science will go in the future," says Peach.

The John Adams Institute, founded in 2004 by the UK Particle Physics and Astronomy Research Council, is one of two university-led centres in Britain set up to pursue research and development into particle-physics accelerator science.

Peach says he will be pushing for the building of a linear collider and a neutrino factory to study the conditions shortly after the Big Bang, 14 billion years ago.

$\mathrm{He}$ has awways had a clear idea of his scientific goals - to understand particle physics, as a basis for understanding how the Universe works, and to use accelerator physics for studying what the Universe looks like. But Peach points out that he has not followed any particular career plan over the past ten years. "The jobs came out of the blue," he says.

He believes that enthusiasm is the source of every successful scientific career, and he is keen to tell the next generation so. "Listen to yourself and find out what you are really most excited about, than go for it as hard as you can!" he says.

Despite switching many years ago from directly performing research to managing it, Peach says that he still feels very much like a scientist, not a manager, and that working with researchers gives him a thrill. "It is satisfying to help scientists achieve what they would like to achieve - after all, this is also my interest, " he says.

And in supporting those scientists he expects to get still closer to his childhood passion: he wants to find out where the stars come from. 